\section{Urinary erythrocyte morphology in acute glomerulonephritis}

Recent reports emphasise the importance of examining the morphological features of erythrocytes in urine as an aid to determining their origin (glomerular or non-glomerular)..$^{1-3}$ Finding pronounced distortion of the majority of the erythrocytes favours a glomerular origin and might be especially helpful for diagnosing glomerulonephritis in patients presenting without erythrocyte casts or proteinuria. In two recent blind controlled studies this test had a diagnostic specificity and sensitivity of over $90^{\circ}{ }_{0} .^{23}$ To our knowledge, however, no serial study of the morphological characteristics of urinary erythrocytes has been carried out in cases of acute glomerulonephritis. We present such a study in one case.

\section{Case report}

A 17 year old boy presented with gross haematuria four days after a pharyngeal infection, for which he had been given erythromycin. There was no oliguria, and physical examination showed only arterial hypertension. On admission the serum creatinine concentration was $239 \mu \mathrm{mol} / 1$ ( $2 \cdot 7 \mathrm{mg} / 100$ $\mathrm{ml}$ ), and a 24 hour urine collection yielded $2 \mathrm{~g}$ protein. Kidney biopsy (day 13) showed a diffuse exudative endocapillary proliferative glomerulonephritis with a coarse granular peripheral deposition of $\mathrm{C} 3$.

The diagnosis of acute infectious (poststreptococcal) glomerulonephritis was supported by a low serum $\mathrm{C} 3$ concentration $(28 \mathrm{IU} / 1 ; 22 \mathrm{mg} / 100 \mathrm{ml})$ and an antistreptolysin $\mathrm{O}$ titre of $1250 \mathrm{MU} / \mathrm{l}$. Throat and urine cultures were sterile. An intravenous pyelogram was normal. Bladder catheterisation was not performed. On discharge (day 21) the serum creatinine concentration was $177 \mu \mathrm{mol} / 1(2.0 \mathrm{mg} / 100 \mathrm{ml})$ and one month later $87 \mu \mathrm{mol} / 1(0.98 \mathrm{mg} / 100$ $\mathrm{ml})$. Proteinuria and hypertension had disappeared.

During his stay in hospital fresh clean voided morning urine was examined almost daily. Erythrocytes in uncentrifuged urine were counted in a FuchsRosenthal chamber. Erythrocyte morphology was studied on the sediment stained with Sedicolor and using simple light microscopy, as described. ${ }^{4}$ Rare erythrocyte casts were observed consistently from the first day. The figure shows the changes in the total erythrocyte count and percentage of distorted (glomerular) erythrocytes.

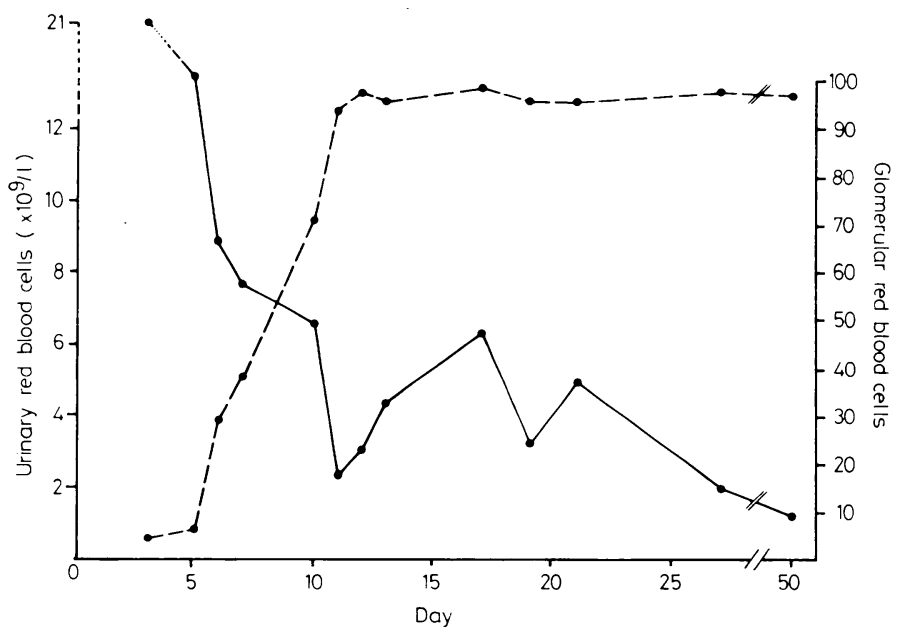

Changes in urinary erythrocyte count (solid line) and percentage of distorted (glomerular) erythrocytes (broken line) in a case of acute glomerulonephritis.

\section{Comment}

This patient presented a typical picture of acute glomerulonephritis, with gross haematuria, erythrocyte casts, and proteinuria on admission. Nevertheless, during the first week the urinary erythrocytes showed predominantly conventional morphological appearances and the count decreased. Only from day 10 was there a clear cut change to a predominantly glomerular morphology, which persisted thereafter in more than $90 \%$ of the cells.

False negative results occur in a minority of cases of glomerulonephritis proved by biopsy. ${ }^{1-3}$ In at least one study this was especially true in patients presenting with gross haematuria. ${ }^{5}$ We present the first serial study, showing an almost inverse relation between the severity of haematuria and the degree of morphological change. This observation emphasises the importance of repeated examination of urinary sediment, which may help to avoid hasty decisions and unnecessary urological investigations in less typical cases.

The observation also argues against the hypothesis ascribing the erythrocyte distortion to physical disruption during passage through the glomerular basement membrane. ${ }^{2}$ More probably the damage occurs in the distal nephron. ${ }^{2}{ }^{3}$ Osmotic forces may be important, but phagocytosis of the erythrocytes by renal tubular epithelium has also been proposed. ${ }^{3}$ Such a process may be less efficient if erythrocytes are present in large numbers. This may explain our findings.

Phase contrast microscopy has been proposed as essential to observe the morphological changes of urinary erythrocytes..$^{1-3} \mathrm{We}$ use an easier and cheaper technique which, in our experience, is more reliable than phase contrast examination. ${ }^{4}$

${ }^{1}$ Fairley KF, Birch DF. Haematuria: a simple method for identifying glomerular bleeding. Kidney Int 1982;21:105-8.

2 Fassett RG, Horgan BA, Mathew TH. Detection of glomerular bleeding by phase-contrast microscopy. Lancet 1982;i:1432-4.

${ }^{3}$ Kincaid-Smith P. Haematuria and exercise-related haematuria. $\mathrm{Br} \mathrm{Med} \mathrm{f}$ $1982 ; 285: 1595-6$.

${ }^{4}$ Hauglustaine D, Bollens W, Michielsen P. Detection of glomerular bleeding using a simple staining method for light microscopy. Lancet 1982 ;ii: 761 .

${ }^{5}$ Chang DS. RBC morphology in glomerular and non-glomerular haematuria. Kidney Int 1982;21:147.

(Accepted 7 fune 1983)

Division of Nephrology, Universitair Ziekenhuis KU Leuven, B-3000 Leuven, Belgium

$\mathrm{PH}_{\mathrm{H}}$ VAN ISEGHEM, $\mathrm{MD}$, assistant inwendige ziekten

D HAUGLUSTAINE, MD, adjunkt-kliniekhoofd inwendige ziekten

W BOLLENS, laboratory technician

P MICHIELSEN, MD, professor inwendige ziekten

Correspondence to: D Hauglustaine, Inwendige Ziekten, Afdeling Nefrologie, A Z St-Rafaël, B-3000 Leuven, Belgium.

\section{Meningitis due to beta lactamase producing type b Haemophilus influenzae resistant to chloramphenicol}

Cases of meningitis due to strains of type b Haemophilus influenzae resistant to both ampicillin and chloramphenicol have been reported only in California ${ }^{1}$ and Bangkok. ${ }^{2}$ We report the first such case in Great Britain. The patient responded to treatment with co-trimoxazole and latamoxef (Moxalactam).

\section{Case report}

A previously healthy $2 \frac{1}{2}$ year old boy presented in January 1983 with a three day history of anorexia, drowsiness, vomiting, and fever. On the day before admission his family doctor had prescribed amoxycillin syrup. $\mathrm{He}$ had been admitted to this hospital twice before with fever and symptoms of upper respiratory tract infection. On examination he was found to be listless and dehydrated with a rectal temperature of $39^{\circ} \mathrm{C}$. Neck rigidity and Kernig's sign were noted. Lumbar puncture confirmed the clinical diagnosis of meningitis, and treatment with intravenous chloramphenicol $300 \mathrm{mg}$ every six hours $(100 \mathrm{mg} / \mathrm{kg} / 24 \mathrm{~h}$ ) and ampicillin $500 \mathrm{mg}$ every six hours was started.

His condition remained virtually unchanged until day 3 , when, in view of reported resistance to the two antibiotics being used, treatment was changed to intravenous co-trimoxazole $6 \mathrm{mg} / \mathrm{kg} / 24 \mathrm{~h}$ and latamoxef $600 \mathrm{mg}$ every six hours. Thereafter his condition improved rapidly. From day 5 co-trimoxazole was given by mouth. On day 7 an urticarial rash and some blistering at the site of the infusion appeared and the intravenous latamoxef was stopped. Thereafter he made an uneventful recovery. Co-trimoxazole was continued for a total of 12 days. Follow up at six weeks did not show any sequelae.

\section{MICROBIOLOGY}

The initial sample of cerebrospinal fluid was turbid and contained $1.5 \times$ $10^{9}$ white blood cells/1 (94\% polymorphonuclear leucocytes). Cerebrospinal 